\title{
What Do Online Students Need And Want From Their Masters Of Business Administration Program?
}

Bahaudin Mujtaba, (Email: Mujtaba@nova.edu), Nova Southeastern University

\begin{abstract}
Computer-based distance education throughout colleges and universities has been in high demand and more schools are getting into online education. As such, understanding the needs of online learners has become especially important for success in the new millennium. Furthermore, understanding the common denominator of technology available to students can assist administrators and faculty members design their admission, teaching and curriculum requirements. This document, based on the survey of 38 graduate online business students ${ }^{l}$, provides an assessment of their views, needs, wants, and satisfaction in the masters of business administration program. Recommendations are provided for the program office to enhance their online offerings are discussed. The document further explores online education, online operation, and other such variables that impact the satisfaction of students in online education. Also, some of the changes, plans and improvements made as a result of the feedback from students are discussed.
\end{abstract}

\section{THE CENTURY OF ONLINE EDUCATION}

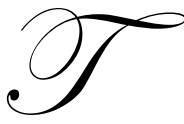

he twenty first century is the first century of comprehensive worldwide online learning both academically and for workforce training. Students in this new millennium can and should be selective in choosing a graduate program for enrollment since a masters of business administration (MBA) program can cost anywhere from $\$ 8,000$ to over $\$ 70,000$ depending on the program and school offering the degree. The business of higher education has become very competitive as schools move far beyond their main campuses to offer programs nationally and internationally. Many of the schools involved in distance education also offer the complete MBA program through the online modality. Learners need not be concerned about the modality of the education programs since many of the same educators who facilitate in the traditional programs are also now teaching at distance education programs. As such, the quality and outcomes achieved are likely to be the same for all programs.

There has been much written about the use of advanced technology in higher education and how best to use that technology in the teaching-learning process, but little research is done each year in each program to survey the students' needs, wants and their overall level of satisfaction with the operation. As such, many programs lose students who really want to finish their degrees through this format of distance education. According to Terry (2001), researchers have found that while online courses enrolled more students compared to onground courses, online courses lost more students to attrition than onground. Distance education holds great promise for schools and adult students but the attrition problem is a concern. Many higher education schools have similarly reported that their online education students have higher attrition rates than onground classroom students. Researchers, academicians and administrators do agree that there is a need for more research about this attrition problem (Henke \& Russum, 2000). A starting place for more research is to assess the level of satisfaction of current online students and determine their capability with regard to technology used for online education. The purpose of this article is to document the level of satisfaction of online students with the online masters of business administration program at Nova Southeastern

\footnotetext{
${ }^{1}$ Special thanks go to Mr. Steve Harvey, Director of the MBA Programs, for distributing, collecting and making improvements as a result of the feedback from students.
} 
University (NSU) and determine their preferences with various elements of the online program. Special attention is paid to such factors as software used, chat sessions, course design, technology, and the learning environment. Also, there is a review of the characteristics needed for an ideal learning environment with technologically savvy learners.

According to researchers (Eastmond, 1998), the term distance education has become synonymous with instruction and facilitation provided through cyberspace technologies via the Internet. As such, many such programs are commonly referred to as online education. Eastmond (1998) discussed three different types of Internet-based courses: first, there is the distance learning programs which are supplemented by use of Internet technologies as a support mechanism as opposed to being the primary medium of delivery; second, there is the computer conferencing medium where Internet is the primary delivery utilizing asynchronous discussions and emails; third, there is the virtual course from the virtual institution where all or most aspects of the course are delivered online. The third format is what Huizenga School has been using for its online program where students can complete all of their program requirements online. However, online students may choose to take some of their courses onground at the main campus or at one of the school's offsite locations. The virtual course has a course facilitator directing discussions, learning, the submission of assignments, and s/he is to provide feedback on a weekly or biweekly basis to students. As a matter of fact, experienced and skilled online facilitators are able to use colorful graphics, audio and video streams, and hypertext links to bring out the learning as well as to involve the various senses of learners to increase their understanding. With a teaching-learning process in the online world, adult students are expected to be actively involved in the knowledge generation process while interacting with the instructor and their colleagues about the material to be learned as guided by the faculty. Faculty members make the difference in student learning as their facilitation skills can be geared toward really learning or simply having students memorize so they can pass an exam. Online faculty members should involve the student in the learning process through their formal and informal facilitation since their involvement can lead to real learning, application and long-term retention. As such, the faculty serves as a facilitator in the learning process as is the case in many of today's non-traditional schools and adult training sessions in the workforce rather than being the primary transmitter of knowledge. This is even more important in the online environment if the material is to be learned, utilized and retained by the graduates of a course or program.

\section{SCHOOL OF BUSINESS AND ENTREPRENEURSHIP'S ONLINE MASTERS PROGRAM}

Many schools are now serving students at distant sites as they have extended their offerings beyond their main campus to national and international locations. For example, since 1984, Nova Southeastern University (NSU) has been offering classes in Jamaica, starting with the Ocho Rios cluster and later expanding to Kingston and Montego Bay. Students travel from across the length and breadth of the island to attend classes at these cluster sites. Today NSU has about 2,000 alumni and nearly 800 active students in Jamaica. Interestingly, Jamaica with its small population of less than three million individuals had the highest enrollment in 2004 for an international site, although NSU has been active in many countries including Bahamas, Trinidad, China, Brazil, France, Germany, Dominican Republic, England, Greece, Panama, France, and Venezuela. Other international Universities facilitating distance education in Jamaica include Florida International University (US), Manchester Business College (England) and University of Dalhousie (Canada). Jamaicans are attracting diverse educational institutions because they want to be globally competitive and economically prosperous.

The Graduate School of Business and Entrepreneurship (SBE) of Nova Southeastern University (NSU) has been offering graduate programs in the fields of business administration through various distance delivery modes nationally and internationally for the past thirty years. One mode of distance delivery of education to adult students has been face-to-face instructor/student interaction in a classroom setting on week nights for one regular quarter (semester). Another mode of distance education delivery has been to meet face-to-face with students on four or five weekends in a given quarter while regularly exchanging assignments and feedback between faculty and students using electronic avenues. A third method of delivery is that students meet several times during the weekdays or evenings for classes during the term. In the late 1990s, the School of Business and Entrepreneurship (SBE) established online programs facilitated through e-University platform, where students could attend all of their courses using the online platforms known as e-University with blackboard technologies. While there are at least four different delivery methods, each format achieves the same outcomes and uses the same textbooks to achieve the stated learning objectives and oftentimes uses the same faculty to teach in different modalities. Each program at SBE surveys and assesses its 
current students as well as its alumni to determine the effectiveness of its operation and curriculum.

The e-University platform was built by the Office of Information Technology (OIT) department at School of Business and Entrepreneurship (SBE) for the online program with input from the faculty and students at the outset. Over time, the e-University platform was enhanced and improved as a result of feedback and requests from students and faculty members teaching courses online. This platform was specifically geared toward the business students at the masters of business programs at NSU. Besides the technical side of online education staff, students and faculty members must also be concerned with the environmental factors of online education. The environmental factors in an online program have to do with time, place, and support from others. Most online students are geographically distant from the institution and from their colleagues. Perhaps their work, career and personal obligations keep these adult learners from attending classes in the traditional format. However, geographical boundaries or the distance from the main campus or one's colleagues does not seem to be a major factor for most online students who are working. Working adult students in the online world are often concerned with time and scheduling constraints which is why they choose to attend classes in this format. Some students choose online education modality thinking that it would save time but this perception is not always true since online courses often take more time with assignments and interaction on the class newsgroups or discussion boards. However, online students do not waste time driving to the classroom as they can attend class through their computers at home, hotels, internet cafes, or work environment (of course, during one's lunch and short breaks). Another advantage of online education is that students can attend class at whatever time of day or night that is best for them. Adult online students face the same challenges as onground students as they need to balance their time and find time for the completion of assignments and group activities. Most online students are required to post assignments asynchronously to the discussion boards in the class several times and submit the required homework. As such, most online students attend class on a regular basis each week instead of a single night or weekend. So, effective time management skills are essential for online students just as much as it is needed for traditional higher education students. Also, the physical workspace for online students is an important environmental factor since most of the interaction with the faculty and others in the class are conducted via the internet. So, it is important that online students have a comfortable workspace because they will be spending much time in this area. As such things like comfort of the chair, spacing of the supplementary books and other resources, appropriate lighting, freedom from distractions, and access to the internet must all be considered. Furthermore, the support of one's family must be sought and appreciated. Unfortunately, without the proper support from one's family members and other important individuals in one's daily routine, online education can become challenging.

There were a total of 382 students enrolled in online business courses in the masters of business administration program during the spring term of 2001. There were 38 online sections of various courses taught through e-University by various full-time and part-time faculty members. An electronic survey was sent to all students enrolled. About 44 students completed the surveys but only 38 surveys were fully completed and used for the analysis providing a return rate of approximately $10 \%$. While students have a choice of taking either online or onground courses to complete their masters program, all students in the masters of business administration program are required to complete the "GMP5014-Information Technology Applications in Management Decisions" online since it is only offered in this modality. Students are required to complete this course during their first few semesters as it is partially designed to familiarize them with the basics of information technology and online research.

The respondents, as can be seen from Table 1, were asked "If offered, what other programs would you pursue online through the School of Business and Entrepreneurship?" About 29\% of the respondents would prefer having the opportunity to take Entrepreneurship specialization online and $26 \%$ would like International Business courses to be offered online as well.

As can be seen from Figure 1, most of the respondents are accessing classroom material from home (84\%) and $5 \%$ of students only have access to the online classroom from their offices. About $11 \%$ of students are able to access online classes both from home and from their office locations. 
Table 1 - Other Programs (Specializations) Desired Online

\begin{tabular}{|l|c|c|}
\hline Specialization or Program & Students & Percentage \\
\hline Entrepreneurship & 11 & $29 \%$ \\
\hline International Business Administration & 10 & $26 \%$ \\
\hline Leadership & 7 & $18 \%$ \\
\hline Human Resource Management & 4 & $11 \%$ \\
\hline Other & 6 & $16 \%$ \\
\hline Total & 38 & $100 \%$ \\
\hline
\end{tabular}

From Home \&

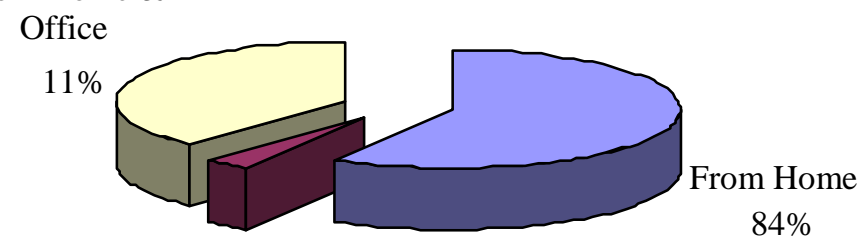

From Office $84 \%$

Over $76 \%$ of online students stated that cable modem or DSL connections are available in their areas and over $44 \%$ of the respondents are using them. However, $46 \%$ of the respondents are using X28K-56K modems to connect to the class. A good number of the respondents, as shown on Table 2, recommend new technologies and features added to enhance their learning and $89 \%$ stated that they would use the added features if made available. The other $11 \%$ that could not use the new features, if added, is due to the fact that their computers or hardware were not capable of handling more features.

Table 2 - Recommendations for New Technology

\begin{tabular}{|l|c|}
\hline Additional Features & Percentage \\
\hline Audio lectures downloadable from the internet & $29 \%$ \\
\hline CD-ROM-based lectures and presentations & $27 \%$ \\
\hline Voice-based chat & $25 \%$ \\
\hline Increase number of relevance of web links & $18 \%$ \\
\hline Other & $1 \%$ \\
\hline Total & $100 \%$ \\
\hline
\end{tabular}

One of the questions asked the following information: "On a scale of 1 to 5 ( 5 being the highest) what is your level of satisfaction with the technology used in the online programs (i.e. text-based chat sessions, bulletin board, course resources to include Power-Point presentations, lecture notes, etc.)." On the satisfaction scale of 1 to 5 (five 
being most satisfied) for this question, over $89 \%$ of the respondents rated the technology used in the online program as 4 or 5 signifying above average level of satisfaction. About $11 \%$ of the respondents marked 3 signifying average satisfaction with no respondent providing a rating of 2 or below to show a less than average level of satisfaction with the technology used in the online courses. Students were also asked for their thoughts on the technology used and the following represents some of their comments:

- Overall the technology for the program has been very good.

- I especially am impressed with the electronic library.

- The voice café chat is a great tool that should be used by more classes/instructors

- The website is very convenient. The website is well planned out and it is easy to access all the information I need. I was very impressed with my first chat session, and find it easy to use the bulletin boards.

- The technology is super. I just need to hear sounds. I need to use all my senses.

- I especially like the voice café used by Dr. Barnes.

- Though I thought I'd miss a lot of the experience due to no face to face, I've come to find that its just as pleasing using the differing technologies.

- I think eShare works well and so does the assignment manager for the most part. Assignment manager should allow for multiple documents to be posted or uploaded for each assignment.

- Text-based chat sessions on its own merits is fine, as are the bulletin board and the other materials, however, the way in which the professors are utilizing these resources are less than desirable. For example, most professors use the first chat session to "make sure that everyone knows how to use the tool," when it would be most beneficial if this type of "training" were optional for more experienced students and required for new students. As a fully computer-literate student, I find attending those first chat sessions a waste of my time. I'd rather talk about actual business issues related to the course.

- I am very satisfied with the bulletin board, chats and the assignment manager.

- PowerPoint presentations are often simply mindless regurgitated textbook charts that are not of any use. Timeouts in chat sessions are too short. These are very minor points. Overall, I am extremely satisfied and would enthusiastically recommend this program to others.

- Sometimes it's difficult to access the video presentations. The PowerPoint presentations often do not provide extra information, but rather just summarize some topics in the chapters. It really doesn't help too much.

- Tried voice café chat in one of my classes. Good concept-however the quality of the audio was bad and many people, including myself, had problems accessing it.

- Technology is fine. However, some of the instructors (majority of the ones I've had) could use the tools better.

One of the questions related to the improvement of technology used in the online masters of business program asked the following content in terms of learning improvement: "On a scale of 1 to 5 ( 5 being the highest), how much do you value the real-time chat sessions?" The results, as can be seen from Table 3, show that about $84 \%$ of the respondents would like to have some type of live interactive chat sessions as they provided scores of 3 or more.

Table 3 - Value of Real-time Chat Sessions

\begin{tabular}{|l|c|c|c|c|c|}
\hline Likert Scale Rating & 5 & 4 & 3 & 2 & 1 \\
\hline Number of Students & 9 & 13 & 10 & 5 & 1 \\
\hline Percentage of Students & $24 \%$ & $34 \%$ & $26 \%$ & $13 \%$ & $3 \%$ \\
\hline & $84 \%$ & \multicolumn{2}{|c|}{$16 \%$} \\
\hline
\end{tabular}

While many students liked the chat sessions, they thought some changes might further enhance their learning experience in the online program. One student mentioned that "Depending on the class size, the chat sessions can cause confusion in trying to read the students comments, form your opinion and answer the professor's questions." The following are some of the other comments with regard to the chat sessions: 
- There usually isn't a lot of contribution from most of the students. Just like at the campus, there are always a small percentage prepared and the rest are along for the ride. Just a note: I hope the teachers don't give out easy "A's", because there is a CLEAR difference in the amount of preparation and knowledge from the learners and the slackers. Also, the main reason I switched from the campus to the online was for flexibility (and to get in an environment where no one was holding me back). So for the chat sessions, often they conflict with my work schedule and since we are graded to a degree on participation that penalizes me. I do not believe "real time" participation should be included in the grade. Scheduling problems are one of the things that online students are trying to solve.

- I think it's valuable to be able to communicate about the topics we are studying. It allows students to really gain an understanding by hearing what others thoughts are and sharing your own.

- They help with getting any questions answered as well as finding out specifics on what the professors expect from us.

- It's nice to have the chats.

- On rare occasions when we do talk about business issues, I value the chat sessions.

- Chatting is the time we really are able to speak with our professors. Because many of the professors will not meet during "office hours" in a chatroom, this is when we are able to ask questions about the chapter, the tests, etc.

- While real-time chat sessions are enjoyable, I feel that they are of limited value. Open study halls moderated by a few professors might be interesting. I really like the idea of audio downloads or CD-ROM lectures/presentations.

- This is the only spot where we interact in a typical manner. Otherwise it is mainly one on one with the instructor.

These comments imply that students like the opportunity to have real-time chat sessions. The feedback further provides a message that there is a lack of consistency in how chat sessions are facilitated and taught. Perhaps the chat sessions can become more consistent in operation in order to minimize student confusion. Also the number of students in each chat session can be limited to a manageable figure to allow for quality interaction among students and the faculty member. A respondent on the survey had written that "Following the chats is challenging...typing, reading and attempting to grasp an understanding of what is being communicated are very difficult at one time." As such, the MBA Program Office added a new feature for online faculty members and students to make the transcripts of each chat session available online, at the request of the faculty member, for students to further review the material at their own pace and time. Some faculty members choose not to make chat session transcripts available online for many reasons including but limited to the fact that they want the chat sessions to be somewhat informal, the material discussed might be available elsewhere on the course resources or discussion board, and perhaps because they want to encourage attendance on each chat session. If the transcripts are available to students who do not attend the chat sessions and chat session attendance is not graded heavily then there is very little incentive for students to attend synchronized interactions. As such, the option of posting the chat session transcripts is left at the discretion of the faculty member and they can choose to make none, one, two or all of their transcripts available to students as per their choosing.

On the satisfaction scale of 1 to 5 (five being most satisfied), over $87 \%$ of the respondents rated the online program as 4 or 5 signifying above average level of satisfaction. About $11 \%$ of the respondents marked 3 signifying average satisfaction with $3 \%$ of the respondents providing a rating of 2 to show a less than average level of satisfaction. Most students seem to have enjoyed their online experience in the masters of business administration program. One respondent wrote "The classes are too work-intensive...The program is designed for working people; however, the on-line portion is so time-consuming that it is impossible to take more than one class if you are to do it justice." Another student stated that "I am really surprised at the level of convenience that this program is offering me. Also I'm surprised at the challenge it has been. I've worked in the military and gone to school on campus before, and this is my most challenging venture so far. I feel I'm going to receive a good education from Nova's MBA program." Some students stated that it is impossible to give an accurate assessment of the eMBA program because each class is a different experience. One student wrote: "For example, the current class I'm enrolled in, the chat sessions are between the students about the homework assignment. No instructions and teaching by the professor." Another student wrote: "I find the eMBA program to be a lot of busy work but with no real connection to the business world. I take ground based classes as well and I understand that being in class is better however, I still believe the eMBA program can be enhanced to include more interaction with the professors." Another student stated that there is always room for improvement in any program. More specifically, "the eMBA program would benefit if students were 
to rely more on the professor's and classmate's discussion of events and a bit less on learning straight from the books...It seems that the professors are there more as mediators than actual professors because although they encourage discussions among students, they rarely participate in sharing their own insights...Most of the learning that students enjoy are as a result of reading the textbook, and not as a result of learning directly from a professor." As such, perhaps the program office can standardize the faculty's participation requirements for each week so students can get more information from the personal experiences and thoughts of each person teaching the course.

The last question on the survey asked "If you were given an opportunity to make changes to the online program, what would they be?" The following are some of the general comments offered by students which show their recommendations, concerns, likes, and dislikes based on their experience during the spring term and prior courses in the online area with the School of Business and Entrepreneurship.

- So far the experience has been great. The addition of audio/CD ROM lecture would be a great asset to the program.

- I really like the program and its flexibility. I do feel that some courses are too heavy on assignments and others are too light.

- I do not really feel I have enough knowledge of the program to recommend any changes at this time. I am very pleased with the program, and will keep my mind open to any changes in the future.

- I would suggest these changes to NSU overall. To raise your standards for entrance. We should not have to spend 8 sessions out of a term reviewing junior college notes in statistics to graduate school business students (verbatim! I found my notes from 10 years ago and compared them). There should be some sort of entrance exam. To get more professors like Dr. Joel Rodgers who challenge you to think rather than memorize; to not have tests from a test bank; to employ professors who have a professional business background--they teach from real world experience vs. the academics who teach only from theory. I always wonder how someone who's spent their whole life on a campus and never been faced with the challenges of managing a business is qualified to know what happens in business and therefore qualified to teach people how to lead one. A final note: I always thought an MBA was a VERY prestigious degree. Now that I'm in the program with other students who clearly don't "get it", I wonder about the validity of my previous assumption. I'm afraid that NSU, like any other business, is out to make a profit. It appears as if you guys will take anyone, get them through the process and hand them an MBA degree just like mine. There is no distinction between those of us (and there are plenty of other students just like me) who invest the time, do the work, learn the material, and the rest who do the least they can to get by, hold the rest of the classroom back, present embarrassing group projects and come out with the same credentials.

- Reduce the workload so more time could be spent interacting on the bulletin board. This would also make the program more attractive and allow for a larger body of students thereof.

- More of an opportunity to see and talk to a professor via video conference or video.

- Offer online audio conferencing. Add voice to the classroom.

- Require DSL/Cable service as it would make me use the service and would make life much easier.

- Make all the classmates' email addresses available so that one can get in contact with a student if they need help on something.

It appears as though students want "Consistency with professors from one term to another as some of them tend to change their requirements-increasing or decreasing it each term." Some students feel that changing requirements from course to course "is not fair when it comes to grading." Furthermore, another student stated that "A slight change would be that professors give more detail in regards to certain assignments... We cannot read minds and at times we are penalized for submitting an assignment we thought was outstanding." Faculty members should publish their grading criteria and rubric in the syllabus and communicate this material to all students on the first week of class to make sure they understand the standards. All grading criteria and rubrics should be analyzed to make sure they effectively reinforce and measure student learning in today's technology-driven learning environment. One respondent on the survey comprehensively commented as follows:

"I believe that term papers or projects on narrowly defined subjects are traditionally dated methods of learning. Instead, it seems that more generalized independent research, reading, and $Q \& A$ testing would be more effective. 
The $Q \& A$ 's could be on related issues, historical occurrences, or current events not found in the textbook. While I find this to be a truly satisfying experience, we have adapted old learning methods to new technology. At some point, we should move on to the next generation of online education and take greater advantage of the capabilities the internet affords us."

Of course, internet offers many possibilities in the twenty first century but such possibilities cannot be realized without breaking the outdated industry rules of the past. Breaking industry rules requires effective training of both faculty members and administrative staff so they can jointly be more flexible in hearing their students' learning needs and so they can be empowered to be innovative in integrating student feedback in the education process while trying new learning strategies. Some students need to have opportunities for face-to-face interaction while they adjust to the online learning world. Perhaps a hybrid format of online and onground sessions or format might be better suited for such students as they attempt to transition from the face-to-face course format to the cyberspace modality of education. The School of Business and Entrepreneurship has successfully implemented the hybrid format of education with students in Brazil and may further look into this option for working adult students who prefer the convenience of online education that are supplemented with face-to-face interactions. One respondent suggested that "I would make it possible for eMBA students to sit in the professors evening courses for extra help...since we are basically learning the same information it would be reinforcement for us because it is hard to get verbal feedback" in the online classes. Allowing and encouraging students to attend a faculty member's traditional class in the evenings, while they are officially registered for the online section, can be an added service to cyberspace learners as they adjust to the online classroom. Of course, very few adult learners may actually take advantage of this option since many of them work on a regular basis. However, such an added service can be another option that provides online learners more flexibility to gain and retain as much information as possible using their dominant learning style.

\section{PLANS AND ACTION TAKEN BASED ON THE FEEDBACK}

As everyone knows, simply gathering data or knowledge without actually making incremental improvements in the operation and enhancing the program is useless. Many individuals have traditionally claimed that "knowledge is power" when in reality that is not really always the case since it is the appropriate use and application of knowledge that can generate power. For example, a person who knows how to read but does not ever read (useful) material is probably not much better than a person who does not know how to read. So, it is the effective use and timely application of knowledge and abilities that can lead to incremental and radical improvements. Luckily, many of the administrators and program managers at the School of Business and Entrepreneurship are making good use of the student feedback in making strategic decisions for enhancing the learning experiences of their students. As a result of the survey in 2001, reported by Mr. Steve Harvey who is the Director of the MBA Programs, the following measures were taken to enhance the program:

- SBE maintained the stated level of chat sessions to ensure direct communication between faculty and students as well as between students themselves. Furthermore, online faculty members were strongly encouraged to hold chat sessions at times convenient to all or most of the students which tend to be evenings for students living and working in the United States. However, occasionally there are students from abroad taking classes online and their time zones should also be taken into consideration when scheduling chat sessions.

- SBE introduced the voice chat software and strongly encouraged its use. This will allow online students and faculty members to actually hear everyone participating in the session in real-time thereby using another mode of their learning to enhance understanding and retention of the material.

- The Program Office maintained other technologies to ensure all students at lower connection speeds could complete coursework. Perhaps, future surveys will show that DSL and cable modem are more readily available for a larger portion of students in order to upgrade technical delivery of coursework as recommended by some students.

- The program office also initiated the development of a standardized online "quiz generator" to better facilitate online quizzes and exams as per faculty members' desires.

- The Program Office made a new feature available to the e-University platform so online faculty members can make the transcripts of each chat session available online for students to further review the material at their own time and pace. 
The Assignment Manager element of e-University was further enhanced and standardized for each course so faculty members teaching different sections of the class can quickly adjust the course based on the pre-established template. This created more consistency with the basic course requirements and provided an avenue to provide feedback to students as soon as they submit each assignment. The grade and feedback for each student is documented on the Assignment Manager and automatically emailed to students at the time of posting. This also made it easier for faculty members to track each student's progress and improvement as they can now go back and review the feedback for each student in previous weeks. The standardization process also made it possible for lead faculty members to add other course related resources such as updated articles, relevant websites, power point presentations, instructor lectures and notes, case studies, and other such items for use by students and faculty members. Furthermore, each faculty member was encouraged to provide a personalized lecturette for each week of his/her class along with relevant guidance to students so they can stay on track and effectively achieve the stated learning outcomes. The lecturettes are usually made available with the course resources or posted on the course's bulletin board at the start of each week along with weekly discussion questions, case studies, debates, team activities, and other relevant assignments to involve students in the achievement of the stated objectives.

The School of Business and Entrepreneurship also planned to begin offering the International Business and Human Resources Management specializations online during 2002 as desired by the respondents. Furthermore, SBE planned to begin offering the Masters of Science in Management with a focus on Leadership online at the end of 2003 once the faculty members are prepared to teach the curriculum online. Furthermore, the SBE Program is consistently enforcing the undergraduate GPA requirement of 2.5 from a regionally accredited institution for accepting students into the master of business administration program in order to make sure students can meet the graduate level standards and academic rigor established in each class. Also, students who have been out of school for many years and need a basic review of the undergraduate material are encouraged to complete some of the prerequisite courses online or they may take undergraduate courses onground or online at times convenient for them in order to be better prepared for the graduate program.

The School of Business and Entrepreneurship is further planning to initiate a pilot hybrid format of the MBA Program at the Main Campus in 2003 for those students who would like to have the opportunity to complete most of their activities online while coming to some onground sessions for interaction with their peers and faculty members. As mentioned before, SBE has successfully implemented a hybrid format of education with international students and this author taught one of the classes with the cluster in Manouse, Brazil in the 1999 academic year. The classes for this cluster would begin online with assignments and interactions each week throughout the semester. During the middle of the term the faculty member would travel to Brazil to hold face-to-face classes with students for three to four consecutive days and evenings. The onground sessions often included lectures, facilitation of concepts, debates, videos, team presentations, individual presentations, and exams. In the next few years, the school is planning to create a similar offering known as "Hybrid Program" for prospective MBA students who live around the Main Campus in Fort Lauderdale, Florida. The program is likely to be about fifty percent online and fifty percent onground to better meet the learning needs of working adult students as they adjust to the cyberspace modality of education while successfully continuing their professional activities. The success of the program will be evaluated based on the satisfaction of students and faculty as well as on the measurements of how well it meets the course learning objectives compared to the alternative modalities. So, a learning assessment study might be conducted to compare the learning outcome of hybrid courses and compare them to the online and onground courses in order to see if there is equivalency in learning when the courses are taught using similar assignments and activities facilitated by the same faculty members. Furthermore, the satisfaction of students and faculty members may be evaluated for the hybrid program to see how the program can be enhanced socially, technically and academically.

\section{CONCLUSION}

Reviewing the above information from the 38 respondents at the School of Business and Entrepreneurship's eMBA Program highlights several points with regard to the needs, wants and satisfaction of online students with the program and how the classes are facilitated. Overall, they seem to be satisfied with their online courses and have several recommendations including consistency of facilitation from course to course, integration of more interaction software with faculty and other students in the class, more involvement of faculty members in the class bulletin board 
on regular basis, feedback from faculty members each week, and stricter enforcement of graduate level standards consistently in each course. Perhaps, the program office can standardize some of the requirements with regard to the chat sessions and provide more intense faculty training for online faculty members so they can provide timely feedback to students each week and participate more often on the bulletin boards while consistently enforcing high standards. Effective faculty participation can assist students stay on target and each faculty can guide students in the right direction by asking leading questions to make sure students are focused on the learning objectives for each week and the course. Furthermore, each faculty member must fairly discriminate, based on a pre-established rubric that is published in the course syllabus, between excellent, good, average, below average, and failing performance on each assignment. Most students appreciate candid feedback that is geared toward their personal and professional development as graduate researchers and practitioners. Besides the aforementioned content, the paper also mentioned some of the changes that have taken place at the EMBA Program since 2001 because of the feedback from students and the availability of resources to further enhance the online program for both students and faculty members.

\section{REFERENCES}

1. Eastmond, D. (1998). "Adult learners and Internet-based distance education". New Directions for Adult and Continuing Education, 78, 33-41.

2. Henke, H. \& J. Russum, (2000). "Factors influencing attrition rates in a corporate distance education program". Education at a distance, 14 (11), Article 03. Retrieved July 25, 2001 from http://www.usdla.org/ED_magazine/illuminactive/ NOV00_Issue/ story03.htm

3. Mujtaba, B., (2004). "What Do Online Students Need and Want from their Masters of Business Administration Program at the School of Business and Entrepreneurship?" Presentation at the International Assembly for Collegiate Business Education (IACBE) Regional Conference. Tuesday, September $28^{\text {th }} 2004$. Orlando, FL.

4. Neely, L., J. Niemi, and B. Ehrhard, (1998). "Classes going the distance so people don't have to: Instructional opportunities for adult learners". T.H.E. Journal, 26(4), 72.

5. Poole, D. (2000). "Student participation in a discussion-oriented online course: A case study". Journal of Research on Computing in Education, 33 (2), 162-77.

6. Richards, C. and D. Ridley, (1997). "Factors affecting college students' persistence in online computermanaged instruction". College Student Journal, 31, 490-495.

7. Roblyer, M. (1999). "Is choice important in distance learning? A study of student motives for taking Internetbased courses at the high school and community college levels". Journal of Research on Computing in Education, 32 (1), 157-71.

8. Rossman, M. (2000). "Andragogy and distance education: Together in the new millennium". New Horizons in Adult Education, 14(1), 3-9. Retrieved from http://www.nova.edu/ aed/horizons/vol14n1.htm

9. Terry, N. (2001). "Assessing enrollment and attrition rates for the online MBA". , T.H.E. Journal, 28 (7), 6468. 